\title{
LA DOCUMENTACIÓN DE LOS NUNCIOS Y AUDITORES PONTIFICIOS: LOS PLEITOS DE FRANCISCO GASCA SALAZAR, ABAD DE SAN ISIDORO DE LEÓN (1599-1621)*
}

\author{
POR \\ María Elena Osorio Alonso \\ Departamento de Patrimonio Histórico y Artístico, Facultad de Filosofía y Letras, \\ Universidad de León
}

\begin{abstract}
RESUMEN
Este trabajo pretende profundizar en la documentación de los nuncios pontificios y de otros oficiales pertenecientes a la curia romana, partiendo de los ejemplos referidos al abad del monasterio de San Isidoro de León, Francisco Gasca Salazar, personaje que protagonizó numerosos pleitos eclesiásticos durante los veinte años que ocupó dicho cargo. Así, además de desarrollar los procesos judiciales, se realiza un estudio diplomático de los documentos de este tipo encontrados en el archivo del propio monasterio de San Isidoro.
\end{abstract}

PALABRAS ClAVE: Diplomática pontificia, nunciatura, Sacra Rota Romana, monasterio de San Isidoro de León, Francisco Gasca Salazar.

\begin{abstract}
This article intends to deepen in the documentation of papal nuncio and other officials of the Roman curia, leaving from the examples sent to the abbot of the monastery of San Isidoro de León, Francisco Gasca Salazar, personage that starred in numerous lawsuits while occupied that position. This way, we try to develop the lawsuits and to make a diplomatic study of this kind of documents, found in San Isidoro's archive.
\end{abstract}

KEY WORDS: Pontifical diplomatic, nunciature, Sacra Rota Romana, monastery of San Isidoro de León, Francisco Gasca Salazar.

* Siglas:

AHN: Archivo Histórico Nacional.

AISL: Archivo de San Isidoro de León. 
La figura del doctor don Francisco Gasca Salazar resulta de gran interés para la historia del monasterio de San Isidoro de León, sobre todo, por el hecho de que, durante los veinte años que permaneció como abad del mismo, no pasó uno solo sin pleitear con su propio cabildo y prior. Así, aunque en su momento, tanto litigio pudiese resultar perjudicial para la vida espiritual y material de este monasterio, la verdad es que, gracias a ello, se conserva gran cantidad de documentación que ayuda tanto al conocimiento de las costumbres del monasterio como de la diplomática pontificia de tipo judicial.

Esta diplomática especial se concreta, en este caso, en documentos intitulados por nuncios pontificios u oficiales de tribunales eclesiásticos dependientes de algún modo de la Santa Sede. Esta documentación no cuenta con estudios concretos y específicos, siendo los existentes muy dispersos, por lo que la abundante documentación enviada a este abad por nuncios y auditores resulta de sumo interés y ayuda para el estudio diplomático e histórico de estas figuras, piezas clave en el conjunto del engranaje burocrático pontificio. Fue el profesor Giulio Battelli ${ }^{1}$ quien señaló la importancia de los documentos que, perteneciendo al ámbito pontificio, no están intitulados por el Papa, pero sí redactados por oficiales de la curia romana y responden al modelo papal en su forma externa e interna, pudiendo estudiarse como una variante de los pontificios ${ }^{2}$.

Pero el tema diplomático se va a relegar a la parte final de este trabajo, pues, aunque ya ha quedado señalada la importancia de los estudios de este tipo de documentación, creo necesario centrarme primero en la figura del abad don Francisco Gasca Salazar, verdadero hilo conductor de estas líneas, y en las situaciones que vivió desde su llegada al monasterio de San Isidoro de León hasta su muerte.

\section{FranCISCO GASCA SALAZAR}

Se conocen pocos datos de la vida del Doctor don Francisco de la Gasca Salazar antes de su llegada al monasterio de San Isidoro. Pérez Llamazares sitúa su nacimiento en el Barco de Ávila, siendo luego canónigo de Palencia, inquisidor de Córdoba y maestrescuela de Salamanca ${ }^{3}$. Desempeñando este cargo Fe-

${ }^{1}$ G. Battelli: «Per una diplomatica dei nunzi pontifici. Un frammento di registro dell'anno 1404», en Miscellanea in memoria de G. Cencetti, Torino, 1973, pp. 539-554. Siguiendo a este autor se encuentra el estudio de J. TRENCHS OdenA: «La cancillería de Albornoz como legado pontificio», en Anuario de Estudios Medievales, 9 (1974/1979), pp. 469-505.

${ }^{2}$ Es el caso de documentos de legados del apéndice documental situado en la parte final de este trabajo, pues éstos representaban al papa y expedían los documentos en su nombre.

3 J. Pérez Llamazares, Historia de la Real Colegiata de San Isidoro, León, 1927, ed. facsímil 1982, p. 190. En lo referente al cargo que Gasca Salazar desempeñó como inquisidor, en la documentación encontrada en el AHN aparece en este puesto en la ciudad de Zaragoza, no en Córdoba como dice Pérez Llamazares. 
lipe II le dio la abadía de San Isidoro, de la que tomó posesión en 1599, permaneciendo en ella hasta 1621, año en que fallece y se le da sepultura en la capilla de Santo Martino.

Gracias a un documento notarial encontrado en el archivo de San Isidoro de León se sabe que tuvo un hermano, el licenciado Diego Gasca Salazar, miembro del consejo de su Majestad y casado con María Ponce de León, quienes murieron dejando una niña, Juana Gasca Salazar Vela ${ }^{4}$. Francisco pasa a ser curador de los bienes de su sobrina, realizándose el documento ante el corregidor y alcaldes de Valladolid en $1608^{5}$.

Por otro documento encontrado en este archivo, se conoce la existencia de un personaje llamado Antonio Gasca Salazar, pero no se ha podido encontrar más información sobre él, ni saber, por lo tanto, el grado de parentesco con el abad de San Isidoro ${ }^{6}$.

\section{EL ABAD Y SUS PLEITOS}

El historiador y abad de San Isidoro de León, Julio Pérez Llamazares, dice de don Francisco Gasca Salazar:

«Quiso cambiar las costumbres en la vida del Cabildo, lo que provocó grandes pleitos con éste, que se resolvieron a favor del Cabildo en Roma. También quiso suprimir la jurisdicción de los priores, para poder nombrarles a su voluntad, lo que provocó pleitos hasta su muerte» ${ }^{7}$.

Efectivamente, los pleitos entre el cabildo y el abad, detallados a continuación, son constantes, siendo una clara muestra de la difícil relación entre ambas autoridades y reflejo de la situación general en la Castilla de principios del siglo XVII, en la que aumentaban los pleitos a la vez que crecía el malestar y la crisis socio-económica ${ }^{8}$.

Sobre su llegada al monasterio de San Isidoro en el verano de 1599, se conservan todas las bulas pontificias para su nombramiento; las dirigidas a los obispos, al rey, al cabildo del monasterio, a los vasallos del mismo y al propio protagonista, Francisco Gasca ${ }^{9}$. Con todos estos documentos en la mano, se

\footnotetext{
4 Mayor de doce años y menor de veinticinco, por lo tanto menor de edad, según se dice en el documento E/19-7 del Archivo de San Isidoro de León (en adelante ASIL).

5 ASIL, E/19-7.

6 ASIL, E/19-14. Se trata de un documento del año 1615.

7 J. PÉrez Llamazares, Historia... op. cit., p. 190.

8 A. Domínguez Ortiz, El Antiguo Régimen: Los Reyes Católicos y los Austrias, Madrid, 1999. En esta obra hay un capítulo dedicado por completo a la crisis del siglo XVII, pp. 259-297.

${ }^{9}$ En formato original o copias se conservan nueve documentos papales en el Archivo de San Isidoro sobre su nombramiento como abad. Documentos 1 al 9 del apéndice documental.
} 
realizaba el acto de toma de posesión de la abadía en la capilla de Santa Cruz del monasterio leonés. Pero además de esta ceremonia - común a todos los abades de este monasterio-, existen noticias de otras dos que se celebraron para completar la toma de posesión del cargo de abad por parte de don Francisco. Una para tomar el hábito de la orden de San Agustín ${ }^{10}$, ceremonia que tuvo lugar en el colegio de Nuestra Señora de la Vega de Salamanca, dependiente de la abadía de San Isidoro, y que incluyó una profesión de la fe católica ${ }^{11}$. En la otra un juez debía tomarle el juramento de fidelidad debido a la Santa Sede, algo que normalmente tenía lugar en la propia ceremonia de toma de posesión de la abadía, pero en este caso se desarrolló en un acto aparte.

Es un hecho destacable, en su proceso de nombramiento, que tuviese que hacer una profesión de la fe católica, pues es el único caso conocido en San Isidoro. Se trata de un formulario enviado desde la Santa Sede, igual al de juramento de fidelidad al que se ha hecho referencia anteriormente, pero en este caso recoge el credo católico. Esto puede deberse a que la época, finales del siglo XVI, es muy convulsa con el afianzamiento del protestantismo, siendo entonces cuando se pone en marcha la maquinaria contrarreformista promovida desde el Concilio de Trento.

Antes de cumplirse un año de su nombramiento como abad de San Isidoro se tiene noticia ya del primer choque entre Francisco Gasca y el prior. El problema surge debido a un auto del abad con fecha del 16 de mayo de 1600 por el que concede la libertad a un preso llamado Juan Martínez Ocón ${ }^{12}$. En este documento no se explica quién es esta persona, por qué estaba encarcelada o cuál es el motivo de su liberación, pero lo interesante del caso es la reacción que tiene el prior de San Isidoro al conocer la noticia de la decisión abacial. Marco Antonio de los Ríos, prior del monasterio, cree que el abad se excede en sus competencias, pues este asunto compete a todo el monasterio y Francisco Gasca debe tratar estos temas con el resto de canónigos antes de tomar este tipo de decisiones. Éste será el inicio de un sinfín de pleitos entre el abad y los sucesivos priores de su monasterio.

Pero no sólo existen desacuerdos dentro de su monasterio. Ese mismo año de 1600 se registran problemas de jurisdicción con el obispo de León, Alonso Moscoso, provocando que este último proclame, en todas las iglesias, la excomunión de Francisco Gasca y de su abadía. Parece ser que todo comienza cuando Gasca confiere las órdenes menores al estudiante Bartolomé Robles, natural de Ruiforco. Según el obispo esto supone una intromisión en su jurisdicción,

10 Existe el ejemplo del abad Marcial Torres en 1636, que también tuvo que profesar como canónigo regular de San Agustín antes de tomar posesión de la abadía de San Isidoro de León.

11 Documento número 11 del apéndice documental.

12 Documento conservado en el ASIL, E/19-3. 
pero el abad pide que se resuelva el caso a su favor porque Ruiforco siempre ha pertenecido a su monasterio. Mientras el asunto se resuelve, se dan otros documentos que avivan el enfrentamiento, como es el caso de un mandato del vicario del abad, Lucas de Valderrama ${ }^{13}$, al rector de la iglesia parroquial de San Pedro, dependiente de San Isidoro, pidiéndole que no lea ningún mandato del obispo si no es aceptado expresamente por el abad de este monasterio. El propio Valderrama es el responsable de un sumario de este proceso que se conserva en el archivo del monasterio de San Isidoro ${ }^{14}$. En él se recoge el testimonio de Bartolomé Robles, estudiante desencadenante del enfrentamiento, que relata cómo lo apresaron las gentes del obispo, manteniéndole preso durante cincuenta días y amenazándole con no darle comida si no decía que Ruiforco era jurisdicción episcopal, algo que el joven no puede aceptar pues afirma que nunca había sido así. También se recoge el testimonio de un vecino de León natural de Ruiforco, llamado Pedro Flórez, que corrobora lo dicho por Bartolomé sobre la jurisdicción abacial del lugar de Ruiforco y además da cuenta del escándalo que ha provocado la difusión por las iglesias de la noticia de que el obispo había excomulgado al abad y a todo el monasterio de San Isidoro. Este conflicto se resuelve cuando el nuncio da la razón al abad y al monasterio de San Isidoro.

Al margen de este caso, sin lugar a dudas, los mayores problemas de Francisco Gasca Salazar se deben al prior y canónigos de su propio monasterio, siendo los enfrentamientos con ellos una verdadera constante de su mandato.

Así, se conservan en el propio archivo del monasterio de San Isidoro de León hasta doce documentos del nuncio Domenico Ginnasio ${ }^{15}$, expedidos entre diciembre de 1600 y marzo de 1602, intentando, en todos los casos, mediar entre el abad y su cabildo para conseguir una vida monástica tranquila. La mayoría de estos documentos van dirigidos a Francisco Gasca tras ser pedida la intervención del nuncio por el prior y el cabildo. En el primer documento encontrado, el prior y los canónigos se quejan ante el nuncio del maltrato que sufren por parte del abad, por lo que el nuncio cree oportuno recordar a Gasca Salazar la necesidad de ser amable con los subordinados. Los siguientes se centran en casos más concretos, como dos documentos sobre la necesidad de escribir todas las decisiones ante notario, pero notarios «libres», ya que según parece, Gasca Salazar coaccionaba a los notarios para que no hiciesen ningún escrito a petición del prior u otro canónigo sin el consentimiento expreso del

13 El documento de Valderrama es del 29 de julio de 1600.

14 ASIL, E/19-4. Sumario del proceso que data del 6 de agosto de 1600.

15 Estos documentos son los números 12, 13, 14, 15, 16, 17, 18, 19,20, 21, 22 y 23 del apéndice documental. Domenico Ginnasio fue nuncio en España entre 1600 y 1605, siendo arzobispo de la diócesis Sipontina (Manfredonia, al sur de Italia) desde 1586 a 1605, luego fue elevado a cardenal $t t$. Sancti Pancratii. Murió en 1639, tras haber desempeñado otros puestos de cardenal y obispo. Cf. en C. EubEL y otros, Hierarchia Catolica, vol. III-IV, Münster-Paduam 1913-28. 
propio abad. Otro de estos documentos trata por primera vez las supuestas irregularidades en el proceso de toma de posesión de la abadía por Gasca Salazar - proceso que se explicará más adelante, pues ocupó varios años de su mandato- - El resto de los documentos dirigidos al abad se refieren al incumplimiento de las costumbres del monasterio ${ }^{16}$ y a la intromisión de Gasca en asuntos que no le competen del prior y de los canónigos, llegando incluso a quitarles las llaves de sus aposentos ${ }^{17}$.

Sólo tres de los doce documentos anteriores no van dirigidos al abad, aunque de todas formas le afectan directamente. Uno está dirigido al prior del monasterio de Benevivere ${ }^{18}$, donde Gasca Salazar mantiene presos al prior y a algunos canónigos de San Isidoro, otro es una comisión del nuncio al prior del monasterio de Santo Domingo de León, sobre el canónigo de San Isidoro, Valderrama, provisor y vicario general de Gasca Salazar ${ }^{19}$. Además, hay un tercer documento dirigido al notario Ventura de Madrid, en el que se le encomienda que, a petición del prior y de los canónigos del monasterio, haga una copia de todos los estatutos y sus reformas para poder utilizarlos en los pleitos que sostienen con el abad.

De fechas posteriores a estos doce documentos, se conservan en el propio archivo de San Isidoro noticias sueltas en las que se siguen viendo los roces entre el abad y su comunidad. Así, en un documento de $1612^{20}$ hay más quejas sobre malos tratos a los canónigos y sobre el incumplimiento de las costumbres del monasterio por parte del abad - según parece no se viste correctamente para acudir al coro- - Hay una copia del testimonio del licenciado Agustín de Parada - preso en el monasterio de Benevivere por Gasca junto al prior y otros canónigos- en el que cuenta los excesos y extravagancias en los gastos de Francisco Gasca, diciendo que el abad no accedía a dar cuenta de sus despilfarros — como el consumo de salmón en Cuaresma- hasta que se lo ordenó el nuncio ${ }^{21}$. Entre estos documentos sueltos también se encuentra otro mandato de $1614^{22}$ del nun-

16 Tiene en prisión y molesta continuamente a Diego de Vega Lorenzana, presidente del convento en ausencia del prior. Documento número 19 del apéndice documental.

17 Documento número 18 del apéndice documental.

18 La abadía de Santa María de Benevívere se encuentra en Palencia. Para más datos L. FERNÁNDEZ, La abadía de Santa María de Benevivere durante la Edad Media, Comillas (Santander), 1962 y L. FERnÁNDEZ, Colección diplomática de la abadía de Santa María de Benevívere (Palencia) 1020-1561, Madrid, 1967.

19 Número 23 del apéndice documental. Tras el documento del nuncio está escrito que se hizo una información en virtud de la cual el nuncio en primero de junio dio otra comisión para que se prosiguiese esta causa y se prendiese al canónigo Valderrama y a Juan García de Arintero. Luego, en el mismo documento hay un memorial del abad Gasca Salazar, diciendo que el prior y convento no siguen las reglas y que están en contra de esos dos canónigos porque saben que son sus vicarios en el monasterio.

20 Documento número 27 del apéndice documental.

21 Copia en el ASIL que data del 26 de marzo de 1703.

22 Documento número $29 \mathrm{del}$ apéndice documental. 
cio Antonio Caetano (1611-1618) para la liberación del prior Cristobal de Quintanilla, a quien el abad encerró en su aposento por ausentarse del monasterio sin su permiso - y era la segunda vez, según testimonio del propio abad-. El desenlace de este caso y los testimonios de sus protagonistas se conocen por unas notas añadidas al final del propio documento legacional por parte del notario en septiembre de 1613. En ellas el prior justifica su ausencia diciendo que fue al priorato de San Nicolás y que no tiene que pedir permiso al abad, porque los permisos dependen del propio prior, según los estatutos del doctor Navarro $^{23}$ y la costumbre. El 19 de octubre el abad le permite decir misa, pero por lo demás le mantiene en su encierro; sólo le quita el castigo durante la Navidad.

Pero aparte de todos estos casos sueltos, se conocen dos pleitos de mayor importancia y extensión en el tiempo. Uno sobre la supuesta irregularidad en la toma de posesión de la abadía por parte de Gasca Salazar y el otro sobre la potestad de nombramiento del prior.

Sobre el primero de ellos, se ha señalado ya la existencia de presuntas irregularidades en el proceso de toma de posesión de la abadía por parte de Francisco Gasca Salazar y parece ser que, aunque el resumen del proceso se conoce por unos traslados de 1607 y $1608^{24}$, éste se fue desarrollando desde los primeros momentos de su mandato, de ahí el documento del nuncio de 1601 anteriormente mencionado.

El resumen del proceso comienza con una petición de demanda del 26 de septiembre de 1601 del fiscal general de la Cámara Apostólica, Vittorio del $\mathrm{Sodo}^{25}$, acusando a Gasca Salazar de no profesar según el Concilio de Trento y reclamando, por ello, los frutos percibidos como abad, que deben destinarse a la Cámara, y pidiendo además que se le prohíba ejercer la dignidad abacial. Con esta misma fecha, el nuncio Domenico Ginnasio envía un mandato citatorio, que es notificado al abad y canónigos de San Isidoro el 9 de noviembre de 1601 por el notario Pedro de Mata. Con fecha del 26 de noviembre de ese mismo año, el fiscal se queja de que no se ha presentado a la citación. También se conserva la defensa del abad a cargo de un procurador ${ }^{26}$. En ella declara que las acusaciones hechas contra él son provocadas por la malicia del prior y canóni-

23 Estatutos de 1555 hechos por Martín de Azpilicueta, llamado doctor Navarro. Más datos sobre este doctor en Aldea Vaquero, Marín y Vives, Diccionario de Historia Eclesiástica de España, vol. I, Madrid, 1972, pp. 167-169. Estatutos originales en Archivo de San Isidoro, ASIL caja 70, n. ${ }^{\circ} 1$.

24 ASIL, E/19-8. Traslado hecho por el notario y secretario de la Cámara Apostólica, Macías González a petición del prior y canónigos de San Isidoro, que se sienten parte interesada en el proceso. ASIL, E/19-10. Traslado de 1608 a petición del abad Francisco Gasca Salazar. Este último traslado incluye en su parte final una serie de argumentaciones de diferentes personas sobre la posible nulidad de la profesión como canónigo de Gasca.

25 Documento que aparece inserto en el número 17 del apéndice documental.

${ }^{26}$ En los traslados del proceso se transcribe la carta de poder que reconoce al procurador de Gasca como tal. 
gos de su convento que han atraído la atención del fiscal sobre su persona por no atreverse a acusarle ellos mismos, pues profesó tras tomar el hábito regular y además presenta las bulas pontificias de su nombramiento. Pero el fiscal responde que esos documentos no dicen que pueda pasar de novicio a profeso antes de un año, que es lo acordado por el Concilio de $\operatorname{Trento}^{27}$, a lo que el abad no responde y el fiscal lo acusa de rebeldía (15 de diciembre de 1601). Al final responde su procurador (20 de diciembre de 1601), repitiendo los argumentos de malicia de su convento, además de decir que, según el Concilio de Trento, el año de espera para profesar sólo es necesario para los novicios jóvenes a los que falta madurez, pero éste no es el caso, pues él ha sido elegido para desempeñar el cargo de abad. Además, según el mismo concilio, si se contraviene esa norma sólo se requiere reconocer la falta, no siendo por ello declarado inhábil y no debiendo tampoco restituir los frutos cobrados. Por último, dice que como abad tiene que profesar pronto para poder gobernar cuanto antes, algo reconocido en el Concilio tridentino ${ }^{28}$ cuando se pide que los abades comendatarios profesen a los seis meses de la toma del hábito. El fiscal Vittorio pide que no se acepten estas argumentaciones de Gasca porque están presentadas fuera de plazo, pero, aun así, argumenta contra ellas, porque, según él, son afirmaciones fácilmente rechazables. Después de todas estas intervenciones el auditor pide el 1 de febrero de 1602 que se presenten las dos partes en litigio.

Pero esto no supone el final del conflicto, pues todavía se requiere la presencia de Gasca en Madrid a petición del prior y canónigos de su monasterio, en virtud de un documento emanado del auditor de la Sacra Rota, Horacio Lancelotto, con fecha del 1 de abril de $1608^{29}$. Pero el abad delega en un procurador alegando que el camino es largo y peligroso, que no está dispuesto a hacerlo, además dice no saber qué papeles debe llevar ni dónde tiene que dirigirse una vez se encuentre en Madrid ${ }^{30}$.

Aparte de este pleito que ocupa prácticamente la mitad de su mandato, se conoce la existencia de otro, también muy extenso en el tiempo, sobre el nombramiento y funciones del prior de San Isidoro. Ya se han comentado con anterioridad los problemas a nivel de competencias que tienen el prior y el abad de este monasterio, pero en el pleito que se va a desarrollar a continuación, se litiga sobre quién tiene la potestad de nombrar al propio prior: el abad o el cabildo.

27 Concilio de Trento, sesión 25, capítulo 15: «No se haga la profesión sino cumplido el año de noviciado y pasados los dieciséis de edad».

28 Concilio de Trento, sesión 25, capítulo 21. Se refiere a que los superiores de los monasterios deben pertenecer a la misma orden, por lo que mandan a los superiores comendatarios que tomen el hábito en seis meses o abandonen la encomienda.

29 Documento número 25 del apéndice documental.

30 Notificación hecha por el notario Agustín Recio de Quirós en León a 19 de noviembre de 1608. 
En el archivo de San Isidoro se conserva la exposición de la situación hecha por un personaje llamado Doctor Matute al rey Felipe III $^{31}$. En ella, el prior y los canónigos dicen que el abad Gasca intenta ejercer la jurisdicción privativamente, cuando, según los estatutos del Dr. Navarro es el prior el que debe tener jurisdicción y coerción en primera instancia sobre los canónigos en las causas criminales.

El Dr. Matute continúa con su exposición del caso al rey. Afirma que el abad rompe las costumbres de San Isidoro con continuas vejaciones y prisiones del propio prior, basándose para ello en dos argumentos, posteriormente refutados por el dicho Dr. Matute. Para el abad, el prior claustral que aparece en los estatutos debe ser su vicario en el monasterio, es decir, su sustituto cuando él no esté presente, pero sin ninguna jurisdicción ni coerción estando el abad. Para desempeñar este cargo debe ser alguien de confianza para el abad, por lo que debe ser nombrado por éste, como en las órdenes benedictina y cisterciense. El segundo argumento se basa en que el papa da al abad la abadía en toda su jurisdicción civil, espiritual y temporal plene in omnibus, así que el prior no puede tener jurisdicción, a no ser que se la dé el propio abad.

A estas afirmaciones sigue la contra-argumentación del Dr. Matute, quien afirma que San Isidoro tuvo desde el principio como superior del monasterio al prior, no teniendo abad hasta el momento en el que pasó a depender directamente de Roma ${ }^{32}$, siendo entonces cuando apareció la figura de abad como superior, pero de un modo similar a lo que había representado hasta entonces el obispo, no quitando por ello las competencias del prior dentro del monasterio.

Con esta situación de confrontación interna en el monasterio de San Isidoro, llegan unos mandatos de Horacio Lancelotto del 6 de abril de $1609^{33}$ por los que requiere la presencia del abad y de los canónigos de San Isidoro, al llegarle quejas sobre la falta de respeto por el abad a la elección de prior hecha por el cabildo.

En León a 19 de septiembre de 1609, ante el notario Antonio de Zafra Argüelles, Gasca defiende su postura de elegir prior, pero la Rota da la razón al prior y canónigos sobre la elección y confirmación de éste por ellos ${ }^{34}$ y concretamente confirma al Doctor Juan Gutiérrez de Lorenzana en el cargo.

31 ASIL, E/19-11.

32 A mediados del siglo XII, el monasterio es elevado a la categoría de abadía exenta de cualquier otra obediencia y jurisdicción que no fuera la de la Santa Sede y se concede a su abad el privilegio de usar mitra, báculo y guantes, siendo el primero el portugués don Menendo (1156-1167). Cf. en M. E. Martín LópeZ, Patrimonio cultural de San Isidoro. Documentos ss. X-XIII, León, 1995, pp. 103-105.

33 Documento número 26 del apéndice documental.

34 Dos sentencias de 1608 y 1618. Son los números 30 y 31 del apéndice documental. 
Se conserva en el propio archivo de San Isidoro una copia auténtica de los ejecutoriales de la Sacra Rota del año 1608 a favor de la jurisdición del prior del Real monasterio de San Isidoro de León y de la conservación de sus estatutos y antiguo gobierno, con la anulación de la visita del licenciado don Pedro de Zamora, visitador apostólico de este Real Convento en virtud de un Breve de su Santidad el señor Clemente VIII de 15 de diciembre de 1603, con cláusula expresa de que informase a la Santa Sede de los problemas que hallase. Pero este hombre se excedió en su misión y procedió contra varios canónigos ${ }^{35}$, dándose por nulo todo lo ejecutado en su visita. También se procede en esta ejecutoria contra el abad Gasca Salazar, que pretendió aprovechar la visita del licenciado Zamora para alterar las costumbres del monasterio de San Isidoro y la jurisdicción de su prior ${ }^{36}$.

Se declaró en la sentencia, además de la nulidad de la referida visita, que dichos prior y canónigos de este Real Convento, estando exentos de la jurisdicción ordinaria e inmediatamente sujetos a la Santa Sede Apostólica, deben conservar el gobierno, régimen, administración, estado y observancia regular en que se hallaban antes de la expresada visita.

Esta sentencia fue notificada en León a 23 de mayo de 1608 por el notario Andrés González Getino al convento y luego al abad Gasca Salazar, quien puso trabas, primero, no dejando entrar al notario en la capilla y, más tarde, intentando quitarle por la fuerza los documentos que debía notificar.

Hay otra copia de los ejecutoriales del año 1618 también a favor de dicha jurisdicción del prior, del derecho de los canónigos de elegir y nombrar a éste trienalmente y sobre la obligación del señor abad de confirmar la elección hecha por éstos. Así, por esta sentencia, se da por válida la elección de prior hecha por los canónigos de San Isidoro en la persona de don Juan Gutierrez de Lorenzana y se da por nula la denegación de confirmación practicada por Gasca Salazar, que es condenado a perpetuo silencio y costas.

Apeló el abad esta sentencia, alegando que como cabeza de este Real Convento le tocaba dicha elección, además de la administración de éste tanto en lo espiritual como en lo temporal.

Se dicta posteriormente una segunda sentencia que confirma la primera: se le impone perpetuo silencio ${ }^{37}$.

35 Aparecen insertos en la primera súplica hecha sobre este tema a Horatius Lacellotus en 1608: Antonio de los Ríos, Juan García de Arintero, Francisco de Gavilanes, Juan Gutiérrez de Lorenzana, Agustín de Parada, Domingo de Mandarozqueta, Andrés Flórez, Cristóbal de Quintanilla, Ludovico de Monsalve, Juan de Montalvo, Frnando de Asensio, Francisco de Villarroel, Francisco Carvallo, Antonio de Córdoba, Claudio de Villafañe y Francisco de Alonitii.

36 Se les condenó en costas, que fueron tasadas en sesenta ducados de oro de Cámara.

37 También se le condenó en costas, pero no resulta su tasación. 
Tras esta sentencia de 1618 ya no hay más noticias de pleitos por parte del abad Francisco Gasca Salazar, siendo posible cierta concordia en la convivencia diaria del monasterio en los años finales de su mandato.

\section{DOCUMENTACIÓN PONTIFICIA}

Después de este repaso por la polémica situación que vivió el monasterio de San Isidoro de León durante el gobierno del abad Gasca Salazar, pasaremos a hacer un estudio diplomático de los documentos que la atestiguan.

La documentación dirigida a don Francisco Gasca se puede clasificar en diplomas papales y documentos emanados de otros cargos pontificios. Los del primer tipo, intitulados por el pontífice y escritos en pergamino, fueron enviados con motivo del nombramiento como abad de don Francisco, mientras que los encuadrados dentro de la segunda clase se conservan gracias a traslados notariales en papel y son de una tipología mucho más difícil de definir.

Los documentos no papales dirigidos a este abad forman un conjunto bastante numeroso debido a los continuos pleitos desarrollados durante su estancia en San Isidoro y además, como se ha dicho en la introducción, resultan ser un tipo documental escasamente estudiado a nivel diplomático ${ }^{38}$.

Aunque estos ejemplos recogidos en San Isidoro tienen como punto en común su carácter judicial, hay que diferenciar las distintas instancias eclesiásticas existentes en este ámbito ${ }^{39}$, pudiendo distinguirse en este caso, principalmente, dos tipos: los documentos intitulados por un nuncio y, por lo tanto, procedentes de su tribunal y los encabezados por un auditor de la Sacra Rota.

Las nunciaturas permanentes se habían ido configurando desde fines del siglo XV. Hasta ese momento la Santa Sede se había hecho representar por enviados o legados de distinto orden: los legati misi, los legados a latere o los colectores ${ }^{40}$. De

38 Los diplomas papales sí cuentan con numerosos estudios diplomáticos: F. LASALA y P. RABIKAUSKAS, Il documento medievale e moderno. Panorama storico della Diplomatica generale e pontificia, Roma, 2003; T. FRENZ, I documenti pontifici nell'medievo e nell'a età moderna, Ciudad del Vaticano, 1989, ed. italiana de S. PAGANO; P. RABIKAUSKAS, Diplomatica pontificia, Roma, 1994, 5. ${ }^{\text {ed. }}$.

39 Los tribunales de la curia romana eran: Signatura Apostólica (constituido a mediados del s. XV), Rota Romana, Penitenciaría Apostólica, Tribunal de la Cámara Apostólica (desde s. XIII para cuestiones pecuniarias), Tribunal auditoris Camerae (juez de todos los prelados, obispos, incluso cardenales. Se ocupaba de causas civiles y criminales, no de asuntos beneficiales y matrimoniales) Cf. en B. KATTERBACH, Sussidi per la consultazione dell'archivio vaticano, vol. II, Referendarii utriusque signaturae a Martino V ad Clementem IX et praelati signaturae supplicationum a Martino V ad Leonem XIII, Ciudad del Vaticano, 1931; M. Teruel y G. DE TEJADA: «Tribunal Eclesiástico», en Vocabulario básico de la Historia de la Iglesia, Barcelona ,1993, pp. 426-435.

40 Para una definición de los legados misi y a latere: «Legados pontificios», en Diccionario de Historia Eclesiástica de España, op. cit., p. 1275. 
todos ellos había llegado a tener cierto carácter de permanencia y continuidad el cargo de colector (nuntius et collector). Tenía la misión de recaudar y enviar a Roma los bienes de la Cámara Apostólica ${ }^{41}$ provenientes de la predicación de indulgencias, diezmos o reservaciones papales, pero a menudo se le encargaban otras misiones, algunas de carácter diplomático, recibiendo para ello facultades especiales, no comprendidas en el propio nombramiento de nuncio y colector.

Se puede afirmar que éste fue el cargo que evolucionó hasta tener las características de nuncio permanente, adquiriendo su forma definitiva en cuanto a sus competencias y organización interna con Gregorio XIII (1572-1585). Los nuncios siguieron dependiendo de la Cámara Apostólica y la correspondencia diplomática la dirigían directamente al papa. Además, siguieron actuando como colectores, pero también como jueces, lo que provocó graves conflictos con las justicias real y eclesiástica ordinaria.

La Nunciatura de la Santa Sede en España se establece con Alejandro VI, siendo Francisco Desprats (1492-1503) el primero en ejercer este cargo siguiendo los desplazamientos de la Corte itinerante de los Reyes Católicos. Esto, junto al envío de un embajador permanente de los reyes ante la Santa Sede desde 1482, demuestra una intensificación de las relaciones entre los monarcas y el pontificado.

A partir de Desprats, se cuenta con una lista prácticamente ininterrumpida de nuncios en España. La mayoría fueron obispos italianos que ejercían también como colectores de la Cámara Apostólica, aunque a principios del siglo XVI hubo también algún nuncio laico.

Tras el Concilio de Trento, con la reforma y establecimiento definitivo de las nunciaturas emprendidos por Gregorio XIII, el nuncio reforzó sus poderes eclesiásticos, convirtiéndose en informador de la Santa Sede y en su agente ante los obispos locales. Su tarea contribuyó a la centralización del gobierno de la Iglesia.

La ocupación principal del nuncio era la negociación política, pero también ejercía funciones administrativas y judiciales, para lo que contaba con un nutrido personal distribuido por varios organismos auxiliares: la colectoría, el tribunal y la abreviaduría. En 1529, Clemente VII otorgó al nuncio la facultad de ejercer como juez de las causas eclesiásticas en apelación, apareciendo la institución conocida como Tribunal del Nuncio. Aunque en principio la medida facilitaba el acceso a la justicia de sus súbditos, que no deberían ir a Roma, esta facultad despertó bastantes recelos y oposición en los reyes, que lo consi-

41 En L. PAszTor, La Curia Romana. Problemi e ricerche per la sua storia nell'età moderna e contemporanea, Roma, 1971, hay una descripción del origen y funciones de la Cámara Apostólica, junto a datos sobre el resto de oficios pontificios; Cancillería y Dataría. 
deraban una intromisión de una jurisdicción extranjera en territorio de su soberanía ${ }^{42}$.

El Tribunal del Nuncio existió entre los años 1529 y 1773, año en el que fue sustituido por el Tribunal de la Rota española. Clemente VII incluyó entre las atribuciones del nuncio la delegación de la plena jurisdicción de los tribunales de la Santa Sede. En España se produjeron quejas, tanto por las tasas exigidas como por juzgar el Tribunal en apelación de los tribunales diocesanos y metropolitanos, pero también en primera instancia ${ }^{43}$.

Los excesos de los nuncios en materia de jurisdicción, provisión de beneficios y percepción de derechos provocaron la protesta generalizada del episcopado español, por lo que el Consejo real, en tiempos de Felipe II, acordó la necesidad de establecer un asesor del nuncio, es decir, una persona natural del reino, pagada por el rey, que viese los despachos que emanasen del nuncio. El papa no quiso ratificar lo acordado por el Consejo. En la segunda mitad del siglo XVI, las pretensiones de la Corona española en materia jurídico-eclesiástica podían reducirse a tres: que se deputasen jueces en España para el conocimiento de las causas eclesiásticas, como en Francia; que se crease una Rota similar a la Romana y que se guardase el orden judicial establecido en el Concilio de Trento ${ }^{44}$. Todo esto cayó en el olvido y con la subida al trono de Felipe III en 1598, cesaron paulatinamente los empeños regalistas, intentándose algunos remiendos a lo ya establecido, pero sin pedir la abolición del tribunal de la nunciatura $^{45}$.

En la documentación enviada al abad de San Isidoro, Francisco Gasca, aparecen los nombres de dos nuncios del período ${ }^{46}$ : Domenico Ginnasio (16001605) y Antonio Caetani (1611-1618).

Se conservan doce documentos en papel enviados por Domenico Ginnasio a la abadía de San Isidoro, a petición del prior y de los canónigos de este monas-

42 Diccionario enciclopédico de los papas y del papado, Barcelona, 2003, Herder editorial, J. M. MARQUÉs, Entre Madrid y Roma. La nunciatura española en 1675, Roma, 1979-80. En este estudio se expone la organización de la nunciatura, con sus distintos oficios, cargos, gastos, etc. Y aunque corresponde a un siglo posterior al que se refleja en este trabajo, resulta de gran interés para conocer los entresijos de este organismo.

43 M. Teruel y G. DE TejadA, Vocabulario básico de la Historia de la Iglesia, Barcelona, 1993, pp. 427-428.

44 Concilio de Trento, sesión XXIV, De reformatione, cap. 20 (en el año 1563). Se quiso tutelar la jurisdicción de los ordinarios prohibiendo a los legados aunque fuesen a Latere, nuncios y gobernadores eclesiásticos u otros, el que, bajo ningún pretexto, ni en virtud de ningunas facultades, conociesen las causas que les competían en primera instancia a los ordinarios.

45 C. García Martín, El tribunal de la Rota de la Nunciatura de España, Roma, 1961, pp. 20-23.

${ }^{46}$ Listado de legados y nuncios en Diccionario de historia eclesiástica de España, op. cit., pp. 1275-1277 y 1286-1287. 
terio, además de un documento en pergamino ${ }^{47}$. Del nuncio Antonio Caetani sólo existen dos ejemplos en papel y uno en pergamino ${ }^{48}$.

Procediendo a su análisis diplomático, se puede apreciar en todos ellos una estructura documental común ${ }^{49}$, imitando en parte el aspecto formal de los documentos pontificios.

La intitulación comienza con el nombre del cardenal seguido de la expresión Dei gratia, el título cardenalicio romano y una precisa indicación de la legación: «Dominicus Ginnassius, Dei et Appostolicae Sedis gratia archiepiscopus Sipontinus Sanctissimi Domini Nostri Papae Clementis diuina prouidentis Papae Octaui eiusdemque Sedis in Hispaniarum regnis cum potestate legati de latere nuntius iuriumque Camerae Appostolicae collectoris generalis». Ésta es la fórmula más completa, pero también aparecen fórmulas abreviadas en las que sólo se menciona el arzobispado y los cargos de nuncio y colector general.

En cuanto a la directio, está en dativo y se usa dilecto nobis in Christo o discreto viro seguido del nombre del destinatario, normalmente Francisco Gasca Salazar.

El saludo que aparece es salutem in Domino ${ }^{50}$.

El cuerpo documental se inicia directamente con una expositio que responde a la siguiente fórmula: «Noueritis pro parte dilecti etiam nobis in Christo (prioris et capituli dicti monasterii) nuper coram nobis fuisse expossitum quod...». Las quejas que se exponen a continuación corresponden, en la mayoría de los ejemplos recogidos en el apéndice documental, a los problemas del prior y de los canónigos con Gasca Salazar, aunque a veces también aparece el nombre propio del prior como sujeto de la queja. En cualquier caso, la súplica termina con la frase «nobisque humiliter supplicatum (fuit) quatenus sibi de oportuno remedio prouidere dignaremur» $\mathrm{u}$ otra fórmula similar.

En cuanto a la dispositio, se trata de mandatos que asemejan en las formas a los documentos papales, pues utilizan la fórmula «te hortamur et rogamus quatenus», propia de las litterae curiales, cuando la orden se quiere expresar de un modo suavizado. Sin embargo, se usa el verbo «mandamus», también propio de las litterae exsecutoriae, para dar una orden clara. En este último caso, se suele añadir el verbo «citamus», pues estos documentos no son sólo mandatos sino, a menudo, también documentos citatorios en los que se pide la presencia de Gas-

47 Los documentos en papel son los números 12 al 23 del apéndice documental. El documento en pergamino es el número 24.

48 Los documentos en papel son los números 27 y 29 del apéndice documental. El pergamino es el número 28.

49 T. Frenz, I documenti pontifici..., op. cit.

50 Según Frenz, a veces se añade sempiternam, pero no se ha encontrado esta palabra en los ejemplos estudiados para esta época.

Hispania Sacra, LVIII

118, julio-diciembre 2006, 517-544, ISSN: 0018-215-X 
ca Salazar o su procurador ante el nuncio para explicar su postura en el caso. También aparecen comisiones a una persona ajena al monasterio para que vea cuál es la situación reinante en él y para ello aparece, junto a «mandamos», el verbo «cometemos» ${ }^{51}$.

Las sanciones incluidas en este tipo de documentos son de índole espiritual — excomunión mayor - y, a veces, también temporal — de tipo pecuniario— si no se cumple lo dispuesto por el nuncio.

La data, según el estilo de la Natividad ${ }^{52}$, sigue este modelo: «Datis Madriti, Toletanae diocesis, anno a Natiuitate Domini millessimo sexcentessimo, die uero nona mensis decembris, Pontificatus praedicti Sanctissimi Domini Nostri Papae anno nono», pero la mayoría de documentos utilizan la forma actual del anno Domini.

La mayor parte de los documentos aquí descritos se conservan gracias traslados que aparecen en los resúmenes de los procesos hechos por distintos notarios a petición del prior o del propio abad del monasterio de San Isidoro, que querían tener una copia de todo lo que había sucedido durante el desarrollo del pleito. Así, aparecen insertos junto a notificaciones, documentos papales y cartas de poder.

Pero no sólo se insertan traslados notariales en los legajos que contienen los pleitos, pues se han encontrado dos documentos originales en papel colocados en medio del resumen de un proceso. Se sabe que se trata de originales porque conservan el sello de papel del nuncio pegado, además de la firma del propio nuncio y la del escribano, que aparece en la parte inferior derecha del folio junto a la fórmula: «Por mandado de su Ilustrísima».

También hay que señalar el hallazgo de dos documentos, uno de cada nuncio, que tienen como soporte el pergamino. En ambos casos se trata de confirmaciones del nombramiento del prior por parte del cabildo del monasterio. Así, se consigue dotar de mayor solemnidad a este tipo de documentos, utilizando pergamino con sello pendiente, mientras que en los otros tipos, como se ha señalado con anterioridad, se utilizaba un sello de papel impreso y pegado.

Por último, hay que mencionar la aparición de otros miembros de la nunciatura en estos documentos. En los documentos revisados, se encuentran con frecuencia los nombres del auditor y del abreviator. El auditor, como juez del tribunal del nuncio, era nombrado desde Roma y progresivamente va a ir ejerciendo sus funciones de una forma bastante independiente del nuncio. En cuanto al abreviador, se puede decir que formaba parte del personal de la abre-

51 Los mandatos de los nuncios aparecen tanto en lengua latina como en castellano, no pudiéndose determinar, con los ejemplos encontrados hasta ahora, el motivo de la utilización de una u otra lengua.

52 Inicio del año el 25 de diciembre. 
viaduría o cancillería del nuncio, a través de la cual éste expedía la documentación judicial y las gracias. Era un cargo de nombramiento pontificio y trabajaba junto a un tesorero, un registrador, un sellador y algunos escribanos ${ }^{53}$.

En cuanto al Tribunal de la Sacra Rota Romana, es conocido que su origen se puede remontar a la actividad desempeñada por los cappellani pontifici en el siglo XIII y por los auditores causarum Sacri Palatii Apostolici del siglo XIV, pero su nombre sólo aparecerá en la documentación pontificia a partir de $1423^{54}$. Hasta el siglo XVI su actividad es muy intensa, pues sus competencias como tribunal del papa eran muy amplias, pero su función principal será la de tribunal de apelación y sus causas siempre se iniciarán a instancia de las partes. A lo largo del siglo XVI se van restringiendo sus actividades, hasta que en el año 1612 Pablo V las limita a las causas matrimoniales y beneficiales.

Los auditores eran nombrados directamente por el papa a través de un motu proprio. Su número quedó fijado en doce en el año 1472 y desde entonces se establecieron tres turnos con cuatro auditores en cada uno para la resolución colegiada de los casos. El auditor general o ponente se encargaba de instruir las causas que llegaban al palacio apostólico, tras recibir una comisión del papa, del vicecanciller o, desde el siglo XVI, de la Signatura iustitiae. Tras proceder al estudio de la causa con ayuda de otros oficiales de la curia, procedía a exponerla ante los cuatro auditores que correspondían al primer turno y el papa, quien debía conceder el decreto Expediatur para que el auditor general pudiese dar la sentencia definitiva. El ponente no tenía voto en la reunión, pero sentenciaba según lo acordado por el resto de auditores ${ }^{55}$.

En los documentos conservados en el archivo de San Isidoro, aparece el nombre de dos auditores: Horatius Lancelottus y Ioannes Baptista Pamphilius ${ }^{56}$.

Por un lado se han encontrado documentos citatorios y por otro, sentencias definitivas.

La estructura diplomática de las citaciones comienza con la intitulación del auditor: «Iuris vtriusque doctor Sanctissimi Domini nostri pape capellanus et ipsius Sacri Palatii Apostolici causarum causaeque et causis huiusmodi auditor

53 J. M. MARQUÉs, Entre Madrid y Roma... op. cit.

${ }^{54}$ L. PASZTOR, La curia..., op. cit. Pero hay distintas versiones de este asunto: V. Russo, La Sacra Romana Rota, 1933, señala la primera aparición del término Rota en la constitución Romani Pontificiis de Martín V de 1424; H. Hoberg, Inventario dell'archivio de la Sacra Rota (sec. XIV-XIX), Ciudad del Vaticano, 1994, ed. J. METZLER, dice, sin embargo, que la denominación Rota se encuentra por primera vez en 1336.

55 H. Hoberg, Hermann: Inventario... op. cit.; V. Russo, La Sacra Romana Rota..., op. cit.

${ }^{56}$ En H. HoberG, Inventario... op. cit. aparece un listado con los procesos en los que aparecen los distintos auditores de la Sacra Rota Romana. Los dos auditores señalados en el texto aparecen entre las pp. 68-76.

Hispania Sacra, LVIII

118, julio-diciembre 2006, 517-544, ISSN: 0018-215-X 
et iudex comisarius ab eodem Sanctissimo Domino nostro papa specialiter deputatus».

La directio responde a la fórmula: «vniuersis et singulis DD. Abbatibus, prioribus, prepositis, decanis, archidiaconis, scholasticis, cantoribus, thesaurariis, succentoribus, sacristis, tam cathedralium quam collegiatarum canonicis, parrochialium ecclesiarum rectoribus seu locumtenentibus, eorundem plebanis, viceplebanis cappellanis, curatis et non curatis, caeterisque presbiteris et clericis, notariis et tabellonibus publicis quibuscunque per ciuitatem et diocesim legionenses ac alias vbilibet constitutis illique vel illis ad quem vel ad quos presentes nostrae litterae peruenerint».

En cuanto al saludo es el típico salutem in Domino, propio también de los documentos de los legados.

Después, en la exposición de motivos, se inserta la comisión dada por el papa: «commissionis cedulam nobis per vnum ex suis cursoribus presentari fecit huiusmodi sub tenore videlicet». En ella el papa pide al auditor que instruya una determinada causa que ha llegado a sus oídos a través de una súplica hecha, en la mayoría de los ejemplos encontrados, por el prior y los canónigos.

Tras la comisión se encuentra la dispositio: «Nos igitur, Horatius Lancellotus, auditor predictus, auctoritate apostolica qua fungimur in hac parte, vos omnes et singulos supradictos et vestrum quomodolibet in solidum committimus et mandamus quatenus (...) nos etiam tenore presentium requirimus et monemus quatenus...».

En estos casos de citación en la sanctio sólo se plantean penas espirituales.

Por último, la data de los documentos citatorios es: «Datum Rome in edibus nostris sub anno a nativitate Domini millesimo sexcentessimo octauo, indictione sexta, die vero prima mensis aprilis pontificatus Sanctissimi Domini Nostri Pauli diuina prouidencia pape quinti anno eius tertio».

Este tipo de documentos se ha conservado en San Isidoro - igual que la mayor parte de la documentación relativa a los nuncios- gracias a traslados notariales, no habiéndose encontrado ningún original.

También se debe a un traslado notarial el conocimiento de las sentencias de la Rota relativas a Francisco Gasca Salazar. En este caso se trata de un traslado del siglo XVIII, hecho en papel y encuadernado con pergamino, en el que se recogen copias auténticas de dos sentencias.

En ellas, la intitulación tiene un carácter mucho más general que en las citaciones, siendo el primero el nombre del rey y el último el del abad, con toda una serie de cargos temporales y espirituales en el medio.

En la expositio se hace un auténtico resumen del proceso judicial, pues se insertan las distintas comisiones papales con las quejas alegadas a lo largo del 
juicio por las partes en pleito e incluso llegan a introducirse sentencias anteriores que fueron recurridas antes de la definitiva, que se inserta en la dispositio con una invocación: Christi nomine invocato.

La data responde al siguiente modelo: «Datum Romae, apud Sanctum Petrum, sub anno a Nativitate Domini millesimo sexcentessimo octavo, Indictione sexta, Die vero mercurii quinta martii, Pontificatus Sanctissimi Domini nostri Domini Pauli Papae quinti anno eius tertio».

Gracias a que este traslado notarial encuadernado es tan exhaustivo, aparecen noticias de cómo eran las letras ejecutorias originales. Se dice que estaban escritas en pergamino, con un sello de cera amarillo en una cajita de madera y pendiente de una cuerda.

En conclusión, se puede afirmar que el largo período en el que Francisco Gasca Salazar estuvo al frente del monasterio de San Isidoro de León se caracterizó por una continua y variada correspondencia con las autoridades judiciales eclesiásticas del período. Si bien, esto no contribuyó en su momento al sosiego espiritual en la vida de la comunidad, hoy en día constituye un magnífico material de estudio para todo investigador interesado por la diplomática pontificia.

APÉNDICE DOCUMENTAL

1599, marzo, 10, Roma, San Pedro.

Litterae exsecutoriae de Clemente VIII a los obispos de León y Salamanca para que se aseguren de que el nuevo abad de San Isidoro, Francisco Gasca Salazar, jure fidelidad al Pontífice y haga profesión de su fe católica.

A. ASIL, 71. Perg. orig. de 277 (+66 de plica) $\times 439 \mathrm{~mm}$. Letra gótica.

B. ASIL, caja 19, n. ${ }^{\circ} 8$ (E/19-8). Papel. Traslado de Macias González del 12 de septiembre de 1607, Madrid. Junto a documento del nuncio Domenico Ginnasio.

C. ASIL, caja 19, n. ${ }^{\circ} 10$ (E/19-10). Papel. Traslado de Macias González del 26 de julio de 1608, Madrid.

1599, marzo, 10, Roma, San Pedro.

Litterae exsecutoriae de Clemente VIII a Francisco Gasca Salazar, presbitero abulense y doctor en leyes, por las que le manda desempeñar correctamente 
su puesto de abad de la misma y también le pide que le envie el juramento de fidelidad debido a la Santa Sede.

B. ASIL, códice CVI, folio 62 .

1599, marzo, 10, Roma, san Pedro.

Litterae gratiosae de Clemente VIII a Gasca Salazar absolviéndole de cualquier pena eclesiástica que pudiera pesar sobre él, para hacer posible su elección como nuevo abad de San Isidoro de León.

B. ASIL, Códice CVI, fol. 63v-64v.

\section{4}

1599, marzo, 10, Roma, san Pedro.

Litterae exsecutoriae de Clemente VIII a los obispos de León y Salamanca y al arcediano de Triacastela, comisionándoles para que den el hábito como canónigo regular a Francisco Gasca Salazar.

B. ASIL, códice CVI, fol. 64v-65r.

C. ASIL, caja 18, n. ${ }^{\circ}$ 8. Papel. Traslado de Macias González, hecho en Madrid el 28 de noviembre de 1608. Junto a documento del nuncio Domenico Ginnasio.

D. ASIL, caja 8, n. ${ }^{\circ}$ 10. Papel. Traslado de Macias González del 26 de julio de 1608.

\section{5}

1599, marzo, 10, Roma, san Pedro.

Litterae curiales de Clemente VIII a Felipe III, rey de España, pidiéndole su apoyo para el nuevo abad de San Isidoro de León, Francisco Gasca Salazar.

B. ASIL, códice CVI, fol. 65r-65v. 
1599, Roma, San Pedro.

Litterae curiales de Clemente VIII al obispo de León pidiéndole su apoyo para el abad Francisco de Gasca Salazar.

B. ASIL, códice CVI, fol. 65v-66r.

1599, marzo, 10, Roma, san Pedro.

Litterae exsecutoriae de Clemente VIII al cabildo del monasterio de San Isidoro comunicando el nombramiento de Francisco Gasca Salazar como nuevo abad y pidiéndoles que le presten la debida obediencia.

B. ASIL, códice CVI, fol. 66r-66v.

\section{8}

1599, marzo, 10, Roma, San Pedro.

Litterae exsecutoriae de Clemente VIII a los vasallos de San Isidoro comunicandoles la elección de Francisco Gasca como nuevo abad del monasterio y pidiéndoles su obediencia.

B. ASIL, códice CVI, fol. 66v-67r.

1599, marzo, 10, Roma, San Pedro.

Litterae clausae o gratiosae de Clemente VIII a Francisco Gasca Salazar para que elija un obispo que le tome juramento de fidelidad a la Santa Sede y posteriormente remita el formulario junto con su sello a Roma.

A. ASIL, 744. Perg. orig. de $344 \times 448 \mathrm{~mm}$. Letra gótica, plica desdoblada, agujeros de haber tenido sello pendiente.

B. ASIL, caja 19, n. ${ }^{\circ} 2$ (E/19-2). Papel. Letra humanística. Traslado del 11 de julio de 1599 hecho en Valladolid por Miguel Sánchez Requejo. 
10

Fórmula de juramento a la Santa Sede del abad don Francisco Gasca Salazar.

B. ASIL, caja 19, n. ${ }^{\circ} 2$ (E/19-2). Papel. Traslado del 11 de julio de 1599, hecho por el notario Miguel Sánchez Requejo en Valladolid.

11

Fórmula de profesión de la fe católica por parte del nuevo abad de San Isidoro de León, Francisco Gasca Salazar.

A. ASIL, 72. Perg. orig. de $449 \times 591 \mathrm{~mm}$. Letra gótica. Buena conservación.

B. ASIL, caja 19, n. ${ }^{\circ}$ 1. Traslado de notario Bartolomé Sánchez del 20 junio 1599.

12

1600, julio, 21, Madrid.

Mandato citatorio del nuncio Domenico Ginnasio al abad de San Isidoro, Francisco Gasca, a partir de una súplica del prior de ese mismo monasterio, Marco Antonio de los Ríos, al que el abad pide la restitución de unas reliquias concedidas a Antonio Vigil de Quiñones por el visitador y reformador Juan Bautista Neroni.

B. ASIL, caja 8, n. ${ }^{\circ} 31$. Este documento se encuentra junto a otros traslados, siendo el número 13 de un total de 14 . Traslado de un notario apellidado García, el nombre no se entiende.

\section{3}

1600, diciembre, 5, Madrid.

Mandato del nuncio Domenico Ginnasio al abad de San Isidoro de León, Francisco Gasca Salazar, para que trate bien a los miembros de su comunidad, que se habían quejado del trato denigrante que sufrían por parte de dicho abad.

B. ASIL, caja 8, n. 31 (documento n. ${ }^{\circ} 10$ de un total de 14 incluidos en la misma carpeta). Letra humanística. Traslado del notario Thomas Vela, sobre otro de Pedro de Mata. 


\section{4}

1601, febrero, 19, Madrid.

Mandato del nuncio Domenico Ginnasio al abad Francisco Gasca Salazar pidiéndole que todo escrito que haga pase antes por un notario libre, debido a las quejas del prior y los canónigos de San Isidoro, que le acusaban de proceder contra ellos de manera irregular -verbalmente o a través de notarios a las órdenes del propio abad-.

B. ASIL, caja 8, n. $^{\circ} 31$ (documento n. ${ }^{\circ} 2$ de un total de 14 recogidos en la misma carpeta). Letra humanística. Traslado del notario Thomas Vela del 24 de febrero de 1601, hecho sobre un documento del también notario Pedro de Mata.

\section{5}

1601, abril, 6, Madrid.

Mandato citatorio del nuncio Domenico Ginnasio por el que pide se presente ante él Francisco Gasca, para que explique su manera de actuar respecto a la figura del prior de su monasterio, San Isidoro de León. Este documento tiene como base las quejas del propio prior y del cabildo, que creen que el abad no respeta los estatutos del monasterio en lo referente a la jurisdicción del prior.

B. ASIL, caja 8, n. $^{\circ} 31$ (documento n. $^{\circ} 5$ de un total de 14 incluidos en la misma carpeta). Letra humanística. Traslado del notario Tomás Vela a partir del escrito del notario Pedro de Mata de la ciudad de León.

1601, abril, 6, Madrid.

Mandamiento del nuncio Domenico Ginnasio en el que agrava las penas impuestas al abad Francisco Gasca en documentos anteriores, porque, según el prior y los canónigos de su monasterio, no ha cumplido ninguno de los mandatos del nuncio que le han sido notificados y ha seguido molestándoles.

B. ASIL, caja $8, n^{\circ} 31$ (documento n. $^{\circ} 9$ de un total de 14 incluidos en la misma carpeta). Letra humanística. Traslado de Pedro de Mata. 
1601, septiembre, 26, Valladolid.

Citación de Domenico Ginnasio a Gasca Salazar a partir de una petición del fiscal de la Cámara Apostólica Vittorio del Sodo, que dice que el abad no ha profesado de manera regular y por lo tanto debe dar los frutos cobrados en ese cargo a la Cámara.

B. ASIL, caja 19, n. $^{\circ}$ 8. Papel. Junto a traslado de dos bulas y dentro de un resumen del proceso contra Gasca por toma de posesión irregular. Traslado de Thomas Vela, sin fecha, que concuerda con el traslado de Macias González, hecho en Madrid a 28 de noviembre de 1608 .

18

1601, octubre, 5, Valladolid.

Mandamiento del nuncio Domenico Ginnasio enviado al abad Francisco Gasca para que liberase al prior y a algunos canónigos que tenía presos en el monasterio de Santa María de Benevivere (Palencia) y para que no se entrometiese en las cosas que no le incumbían dentro de su monasterio, como las rentas de los canónigos o las llaves de los aposentos, sus ropas o sus libros, todo ello confiscado por el abad según su criterio.

B. ASIL, caja 8, n. $^{\circ} 31$ (documento $^{\circ} .^{\circ} 11$ de un total de 14 recogidos en la misma carpeta). Traslado de Tomás Vela sobre otro de Pedro de Carvallo.

1601, noviembre, 8 , Valladolid.

Mandato del nuncio Domenico Ginnasio ordenando al abad Gasca Salazar que libere de prisión al presidente de su convento, Diego de Vega Lorenzana, que debe ejercer las funciones del prior en ausencia de éste y estando preso deja el monasterio sin el debido gobierno. simple.

B. ASIL, caja 8, n. $^{\circ} 31$ (documento $n .^{\circ} 6$ de un total de 14). Letra humanística. Copia 
1601, diciembre, 7, Valladolid.

Mandato del nuncio Domenico Ginnasio por el que ordena al escribano de León, Ventura de Madrid, y a cualquier otro que tenga conocimiento de los pleitos entre el abad y el monasterio de San Isidoro, que hagan traslado de los estatutos de dicho monasterio a petición del prior y de los canónigos del mismo.

B. ASIL, caja 63, n. ${ }^{\circ}$ 8. Letra humanística. En legajo del notario Buenaventura de Madrid Santisteban con fecha 11 diciembre 1601, León, a partir de un documento del notario Francisco Martínez de Luna. Hay dos copias de este documento (1. ${ }^{\circ}$ y $3 .^{\circ}$ del legajo).

1602, enero, 24, Valladolid.

Mandamiento del nuncio Domenico Ginnasio por el que manda al abad Gasca Salazar que no proceda contra el presidente de su monasterio, Diego de Vega Lorenzana, pues, aunque le ha liberado de prisión como había pedido el nuncio en un documento anterior, no le deja ejercer las funciones propias del cargo que ocupa.

A. ASIL, caja 8, n. ${ }^{\circ}$ 32. Letra humanística. Marca de haber tenido un sello pegado. «Notario Francisco Martínez de Luna, por mandado de su Ilustrisima».

1602, marzo, 17, Valladolid.

Mandato del nuncio Domenico Ginnasio por el que manda al prior del monasterio de Santa María de Benevivere (Palencia) que cumpla el auto del propio nuncio, dado en Valladolid el 13 de marzo de 1602, en el que se pide la liberación del prior de San Isidoro de León, Marco Antonio de los Rios, y de otros canónigos presos por orden del abad Gasca Salazar. Aparece inserto el auto del nuncio.

A. ASIL, caja 63, n. ${ }^{\circ}$ 10. Letra humanística. «Por mandado de su Ilustrísima, lo hizo Francisco Martinez de Luna».

Hispania Sacra, LVIII

118, julio-diciembre 2006, 517-544, ISSN: 0018-215-X 


\section{3}

1602, marzo, Valladolid.

Comisión del nuncio Domenico Ginnasio por la que encarga al prior del monasterio de Santo Domingo de León que haga un informe sobre el vicario de San Isidoro, Valderrama, para ver si son ciertos los excesos y delitos de los que le acusan el prior y otros canónigos de ese monasterio.

B. ASIL, caja 8, n. ${ }^{\circ} 31$ (documento n. ${ }^{\circ} 12$ de un total de 14). Letra gótica. Copia simple.

\section{4}

1602, abril, 23, Valladolid.

Documento del nuncio Dominico Ginnasio enviado al capítulo de San Isidoro en que confirma la elección del prior Diego de Vega Lorenzana y a la vez da comisión al arcediano de Mayorga para que observe que éste puede desempeñar sus funciones correctamente.

A. ASIL, caja 63, n. ${ }^{\circ}$ 9. Letra humanística. Perg. Orig. $277(+36) \times 340 \mathrm{~mm}$. Letra humanística. Se conserva la cuerda de la que estaría pendiente el sello.

\section{5}

1608, abril, 1, Roma.

Comisión del auditor de la Sacra Romana Rota, Horacio Lancelotto, para que todo aquel que sea requerido participe en el proceso contra el abad de San Isidoro, Francisco Gasca, acusado de una posible irregularidad en su profesión como canónigo de ese monasterio. Aparece inserta la comisión papal que encomienda el caso a Horacio Lancelotto y expone los motivos presentados por el prior y los canónigos de San Isidoro para iniciar este proceso. Según ellos, el abad no cumplió las normas del Concilio de Trento en su profesión como canónigo, pues no pasó el año de noviciado requerido en éstas, por lo tanto no puede ejercer el cargo de abad.

B. ASIL, caja 8 n. ${ }^{\circ} 10$ (B-a/8-10) Pliego de papel. Traslado del notario Andrés Gómez de Vedoya. Letra cursiva pequeña. 1608

C. ASIL, caja 19, n. 9 (E/19-9). Traslado de Agustín Recio del 12 de noviembre de 
D. ASIL, caja 19, n. ${ }^{\circ} 8$ (E/19-8). Traslado del notario Macias González, Madrid, 28 noviembre 1608.

E. ASIL, caja 19, n. ${ }^{\circ} 6$ (E/19-6). Traslado en papel de Andrés Gómez de Vedoya hecho directamente del original, que era un pergamino con sello en caja de madera y pendiente de cuerda de cáñamo. No aparece fecha de la copia.

F. ASIL, caja 9, n. ${ }^{\circ} 11$ (E/19-11). Copia simple.

\section{6}

1609, abril, 6, Roma.

Comisión del auditor de la Sacra Romana Rota, Horacio Lancelotto, a todas las personas que pudieran ser requeridas en el proceso contra el abad Gasca Salazar por no querer confirmar el nombramiento de prior de San Isidoro hecho, según la costumbre, por el capítulo del mismo. Aparece inserta la comisión del papa adjudicando el caso al auditor y exponiéndole las quejas del presidente y canónigos de San Isidoro que no conseguían la confirmación abacial para su candidato a prior.

B. ASIL, caja 63, n. ${ }^{\circ} 15$ (I-a / 63-15). Letra humanística. Dos pliegos de papel. Traslado del notario Antonio de Zafra Argüelles, en la ciudad de León a 16 de septiembre de 1609.

1612, agosto, 22, Madrid.

Mandato del nuncio Antonio Caetani al abad Francisco Gasca Salazar para que entregue todos los documentos que tuviese sobre los canónigos de su monasterio al archivista del mismo, que es la persona que debe tenerlos, no proceda contra los demás canónigos y para que acuda al coro vestido como es debido. Este mandato se produce a partir de una súplica hecha al nuncio por el presidente y el capítulo de San Isidoro, que dicen que el abad retiene en su poder informaciones sobre la limpieza y las costumbres de los nuevos canónigos, asi como también, procede a castigar a todos aquellos que salen del monasterio con permiso del presidente. Además no se viste correctamente para acudir al coro.

B. ASIL, caja 19, n. ${ }^{\circ}$ 5. Copia simple. 


\section{8}

1613, julio, 13, Madrid.

Confirmación de Cristobal de Quintanilla como prior de San Isidoro por parte del nuncio Antonio Caetano.

A. ASIL, 124. Pergamino original.

1614, febrero, 1, Madrid.

Mandato del nuncio Antonio Caetani enviado al abad Gasca Salazar para que cumpla una orden anterior, por lo que le agrava las penas impuestas. En la exposición de motivos del mandato se dice que se expide a instancias del prior y canónigos de San Isidoro, que piden la liberación del licenciado Cristobal de Quintanilla, a quien el abad mantiene preso no aceptando los mandatos anteriores del nuncio que también pedían su liberación.

B. ASIL, caja 8, n. ${ }^{\circ}$ 33. Letra cursiva. Notario Juan Bautista de Torres.

\section{0 y 31}

1608, marzo, 5, Roma.

Sentencia del auditor del Tribunal de la Sacra Rota, Horacio Lancelotto, en el proceso abierto contra el abad de San Isidoro de León, Francisco Gasca Salazar, sobre la jurisdicción del prior de dicho monasterio. Se insertan los siguientes documentos:

Comisión del papa sobre Pedro de Zamora, visitador en el año 1603 de las iglesias y monasterios de la orden de San Agustín de la zona de Castilla y de León, con autoridad apostólica para acometer reformas en ellos. Se excedió en sus funciones metiendo en prisión a varios canónigos de San isidoro de León, por lo que el prior y los canónigos de ese monasterio elevaron una súplica sobre esta actuación al Papa.

Segunda comisión papal, también a instancias del prior y de los canónigos de San Isidoro sobre el dicho visitador Pedro de Zamora, que, alegando que tenía poder para ello, acabó con la costumbre de elegir prior por parte del capítulo de San Isidoro, lo que hizo elevar esta súplica a su Santidad. A raiz de esto se declaró la visita en suspenso hasta poder verificar los hechos. 
Sentencia definitiva de Horacio Lancelotto por la que declara nula la visita de Pedro de Zamora al monasterio de San Isidoro y revoca todos los cambios efectuados en virtud de ella en dicho monasterio - encarcelaciones y cambios en las costumbres-. Además se pidió la presencia de las dos partes en conflicto, pero sólo se presentó la parte del prior y de los canónigos, no apareciendo ni el abad, Francisco Gasca, ni el visitador Pedro de Zamora, por lo que se les condena al pago de sesenta ducados de oro.

1618, enero, 15, Roma.

Sentencia del auditor de la Sacra Rota romana, Juan Bautista Pamphilio, en el proceso abierto entre el abad, Francisco Gasca y los canónigos de San Isidoro sobre quién tenía la potestad para nombrar prior. Aparecen insertos los siguientes documentos:

Comisión papal al auditor Horacio Lancelotto sobre la costumbre del capítulo del monasterio de San Isidoro de León de elegir prior.

Sentencia definitiva de Horacio Lancelotto a favor de la elección de prior por parte del capítulo del monasterio. Además confirma la elección hecha en la persona de Juan Gutiérrez de Lorenzana, a quien el abad, Francisco Gasca, se había negado confirmar en el cargo. Condena al abad a perpetuo silencio.

Dos nuevas comisiones papales, en este caso al auditor Juan Bautista Pamphilio, a partir de la apelación hecha por el abad Fancisco Gasca a la primera sentencia del auditor Horacio Lancelotto.

Sentencia definitva de Juan Bautista Pamphilio que confirma la primera hecha por Horacio Lancelotto, condenando al abad Gasca Salazar a perpetuo silencio y una cantidad no especificada.

B. ASIL, caja 65 n. ${ }^{\circ} 1$ (I-a/65-1). Letra humanística. Dos documentos (1608 y 1618). Papel, pero encuadernado en pergamino. Traslado del notario Antonio de Nava y Robles, hecho el primero el 4 de junio de 1760 y el segundo el 10 de junio de 1760 . En la portada se puede leer: «LEG. ${ }^{\circ} 1^{\text {o }}$ N. ${ }^{\circ} 11$. Copia auténtica de los executoriales de la Sacra Rota del año de 1608 a favor de la xurisdición del señor prior de este Real de San Ysidro de León y de la conservación de sus estatutos y antiguo gobierno, con la anulación de la visita de Zamora. Y a su continuación otra de los de el año de 1618 también a favor de dicha xurisdición del señor prior y sobre la obligación del señor abad a la confirmación de su elección \&c». 